\title{
Über Selbsttests
}

\section{Eberhard Wolff}

Prof. Dr. rer. soc., Redaktor Kultur, Geschichte, Gesellschaft

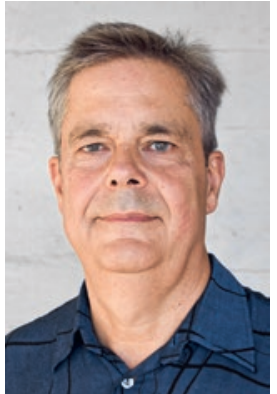

Es gab sie wirklich, die «Stumme Schwester» aus Thomas Manns Sanatoriums-Roman Der Zauberberg. Ein Fieberthermometer ohne Skala. Diese konnte das Personal nach der Messung aufsetzen und für sich den Wert ablesen. Die womöglich Fieber simulierende Patientenschaft sollte ihre Körpertemperatur nicht selbständig in Erfahrung bringen.

Das Fieberthermometer markiert seit den 1850er Jahren den Einstieg in die moderne messende und testende Medizin. Als der Schweizer Arzt Aimé Mercier seine "Stumme Schwester» 1896 auf den Markt brachte [1], waren häusliche Fieberthermometer für die Selbstmessung bereits Alltag.

Eine medizinische Zeitschrift empfahl die «Stumme Schwester» damals bei «neugierigen» Patienten. Heute gilt sie als ein Kopfschütteln erregendes Kuriosum eines autoritären Arzt-Patienten-Verhältnisses, das einseitig auf ein Handlungs- und Wissensmonopol sowie Kontrolle aufbaut. Als Ausdruck eines Misstrauens in die Patientenschaft. Und wie so oft wurde Entmündigung mit dem Argument der Fürsorge verschleiert: Das Verheimlichen der Temperatur solle etwa dem Schutz leicht erregbarer Patientinnen dienen.

Der «Informed Consent» verbietet es der heutigen Medizin, der Patientenschaft ein Mess- oder Testergebnis vorzuenthalten. So etwas gibt es nur noch bei diesen speziellen Parkuhren, welche die vom Vor-Parkierenden bezahlte Restzeit verheimlichen und sich damit Doppelbezahlungen erschleichen.

Die «Stumme Schwester» wurde zum Flop. Viele Werte wurden bald genauso selbstverständlich von den Gemessenen und Getesteten selbst erhoben wie die Körpertemperatur: Gewicht, Blutdruck, Schwangerschaft und all das, was heute ein Smartphone zu messen vermag [2]. Die Patientenschaft sollte damit mehr Verantwortung für ihre gesundheitlichen Belange übernehmen. Etwa bei der täglichen Blutzuckerbestimmung durch Zuckerkranke. So viel Verantwortung, dass manche schon kritisierten, hier würde die Gesundheitsverantwortung in neoliberaler Manier auf die «Kunden» abgeschoben. In der Praxis gab das professionelle System die Verantwortung aber nur selektiv und recht kontrolliert ab. Wenn es «ernst» wurde, war das Vertrauen in die von der Klientele erhobenen Ergebnisse oft ziemlich beschränkt.

Das zeigte uns gerade auch der einfach zu handhabende Covid-Antigen-Schnelltest, als er dieses Früh- jahr als Selbsttest parat war. Im Vorfeld wurden Vorbehalte gegenüber der «Zuverlässigkeit» der Bevölkerung geäussert und vor einem epidemiologischen Kontrollverlust bei Selbsttestung gewarnt. Für den eigenverantwortlichen Beitrag zur Pandemiebekämpfung gab es aber doch zumindest fünf Testkits pro Monat umsonst.

Mit der bundesrätlichen 3G-Zertifikatspflicht vom 13. September wurden die «offiziellen» Tests zum Türöffner für das zugangsgeregelte öffentliche Leben der Hallenbäder, Bibliotheken etc. Sie waren es aber nicht, wenn man ein identisches Antigen-Testkit zu Hause verwendet hatte. So weit ging das Vertrauen dann doch nicht.

Österreich setzte dagegen zur gleichen Zeit auf zertifizierende "Wohnzimmertests». Deren per App und QR-Code (ohne Video-Aufsicht) hinterlegte Ergebnisse liefern ein «Do-it-Yourself-G» für den Zutritt zum öffentlichen Leben [3]. Die Wiener Regierung entzog ihren Bürgern das Vertrauen ins Selbermachen bald wieder. Der Rest Österreichs soll offenbar bei steigender Intensivbettenbelegung folgen.

In der Schweiz sind deutlich zaghaftere Versuche einer Eigenverantwortlichkeit der Getesteten schon in der Ideenphase stecken geblieben. Über die Gründe mag man spekulieren. Marktmonopole? Sicherheit? Professionelle Autorität? Vorauseilendes Misstrauen? Oder dreht sich alles darum, "fürsorglich» den Impfdruck zu erhöhen?

Der Status von Selbsttests in unserer Gesellschaft ist selber ein gutes Messinstrument für das Vertrauen [4] oder besser Misstrauen, das ein Medizinsystem seinen Patientinnen und Patienten oder eine Regierung «ihrem Volk» entgegenbringt.

Die echte "Stumme Schwester» von früher gibt es heute nur noch im Museum zu sehen. Viele nahe und entfernte Verwandte der «Stummen Schwester» können wir aber um uns herum entdecken.

Literatur

1 Mörgeli C. «Die stumme Schwester». Ein Fieberthermometer in der Weltliteratur. Pneumologie. 2007;61:31-4.

2 Weitere Literatur in Wolff E. Das "Quantified Self" als historischer Prozess. Die Blutdruck-Selbstmessung seit dem frühen 20. Jahrhundert zwischen Fremdführung und Selbstverortung. Medizin, Gesellschaft und Geschichte. 2018;36:43-83.

3 Zum Beispiel: www.selbsttest.tirol

4 Ritzmann I. Vertrauen als Mittel zur Patientenbindung - Historische Blicke auf eine ärztliche Strategie. In: Baer J, Rother W (eds.) Vertrauen. Basel: Schwabe; 2015, p. 131-51. 